\title{
Hyperbaric oxygen and multiple sclerosis: final results of a placebo-controlled, double-blind trial
}

\author{
MICHAEL P BARNES, DAVID BATES, NIALL E F CARTLIDGE, \\ JOYCE M FRENCH, DAVID A SHAW
}

From the Department of Neurology, Royal Victoria Infirmary, Newcastle upon Tyne, NE1 4LP, UK

SUMMARY The long term results are reported of a trial involving 120 patients with chronic multiple sclerosis who were randomised to receive either $100 \%$ oxygen at 2 atmospheres absolute (ATA) for 90 minutes daily for 20 sessions or placebo therapy with air using a simulated compression procedure. The previous finding of subjective improvement in bowel/bladder function at the end of treatment was not confirmed by objective urodynamic assessment. The treatment did not alter disease progression as measured by the Kurtzke disability status scale nor did it alter the rate of acute relapse. There was less deterioration in cerebellar function at one year in the treated patients, as measured by the Kurtzke functional systems scale. No other differences were found between the two groups. Psychometric tests and measurements of lymphocyte sub-populations showed no treatment related effects. Evoked potential studies showed no improvements but there was a significant reduction in amplitude of the visual evoked potential in the treated patients at the end of therapy. This might indicate a reversible degree of retinal damage induced by oxygen toxicity.

In a previous paper $^{1}$ we described the short term results of a study of the effects of $100 \%$ oxygen at 2 atmospheres for 20 daily sessions of 90 minutes duration in patients with chronic multiple sclerosis. A total of 120 patients with clinically definite multiple sclerosis were randomised to receive either hyperbaric oxygen or normal air at normal atmospheric pressure within the same compression chamber. The clinical assessment at the end of treatment showed that no patient in either group had improved on the Kurtzke disability status scale. ${ }^{2}$ The only significant change on the Kurtzke functional systems scale $^{2}$ was an improvement in 12 of 51 patients in the oxygen group compared with 3 of 47 control patients on the subjective bowel/bladder item. Our short-term findings have now been generally confirmed by a further six doubleblind, placebo-controlled trials involving a total of 264 patients. $^{3-8}$

We now report the results of the clinical assessments made 6 and 12 months after completion of treatment. We also report the results of ancillary investigations conducted before and after treatment:

Address for reprint requests: $\operatorname{Dr} M$ P Barnes, MD, MRCP, Department of Neurology, Royal Victoria Infirmary, Queen Victoria Road, Newcastle upon Tyne NE1 4LP, UK.

Received 2 December 1986 and in revised form 31 March 1987. Accepted 2 April 1987 evoked potentials, urodynamic tests, psychometric tests and measurements of the lymphocyte subpopulations OKT3, OKT4 and OKT8.

\section{Methods}

The inclusion and exclusion criteria for this study and details of the randomisation and compression procedures have been documented in our previous paper. ${ }^{1}$ A total of 60 patients in the oxygen group and 57 in the control group completed the requisite number of 18 sessions.

\section{Clinical assessment}

Each patient was examined by a clinical neurologist (DB or NEFC) who was unaware of the patient's randomisation. Each patient was seen by the same examiner immediately before and after the treatment period and 6 months and 1 year later. The examiner graded the patients' disability on the Kurtzke disability status scale (DSS) and the Kurtzke functional systems scale. ${ }^{2}$ A note was made of whether the patient reported subjective improvement and, if so, how long the improvement had lasted. The number of acute relapses since the previous examination was also noted.

As previously, a marked improvement or deterioration was defined as a movement of one grade on the Kurtzke DSS and a mild improvement or deterioration was defined as a one point change on the Kurtzke functional systems scale.

Evoked potential assessment

Thirty patients from each treatment group were randomly 1402 
selected to have visual and somatosensory evoked potentials performed by standard techniques. These were carried out in the week before and the week after treatment and 6 months later.

\section{Urodynamic assessment}

Twenty patients from the oxygen group and 20 patients from the placebo group were randomly selected to have a full urodynamic assessment, including micturating cystourethrography, by standard techniques. This was performed in the week before and the week after treatment and at 6 months. The patients were also asked to give a detailed history of urinary symptomatology.

\section{Psychometric tests}

A total of 100 patients (50 in each group) were randomly selected to undergo a short battery of psychometric tests. The battery consisted of the Trail Making Test, ${ }^{9}$ the Rey auditory verbal learning test, ${ }^{10}$ a finger tapping test, the Digit Symbol Substitution test of the Wechsler Adult Intelligence Scale and the Controlled Word Association Test. ${ }^{11}$ This battery examines aspects of memory, manual dexterity, visual tracking and speech fluency, all of which may be impaired in multiple sclerosis. ${ }^{12}$ The battery was administered in the week before treatment and immediately at the end of the final treatment session.

\section{Lymphocyte sub-populations}

Blood was withdrawn from 31 randomly selected patients (16 in the oxygen group and 15 in the control group) for assessment of the lymphocyte sub-populations using the commercially available monoclonal antibodies, OKT3, OKT4 and OKT8. The sub-populations were identified by standard techniques using indirect immunofluorescence and visual counting. Each patient had blood taken, at the same time of day, in the week before treatment and on day 8 and day 18 of treatment and again 3 months later.

\section{Results}

\section{Data analysis}

Data from this study was transferred to a computer file on the University of Newcastle IBM 360/370 computer. The data was analysed by use of the SPSS-X batch system (SPSS Inc, Chicago, USA).

\section{Clinical assessments}

One man in the placebo group died from a myocardial infarction between the completion of treatment and the 6 month assessment. All the other patients were seen at 6 months and at 1 year. Table 1 summarises the changes found in the Kurtzke DSS. There are no significant differences between the two groups. Tables 2 and 3 summarise the changes on the Kurtzke functional systems scale. The short term improvement that was found in bladder function ${ }^{1}$ was sustained at 6 months but not at 1 year.

The only long term benefit to be found was that five oxygen patients had deteriorated in cerebellar function at 1 year compared with 15 control patients $(p<0.05)$. There was a trend towards less deterioration in sensory function but this failed to reach statistical significance. Oxygen therapy had no effect on relapse rate (table 4). Thirty two patients in the oxygen group and 27 controls had felt overall subjective

Table 1 Change in Kurtzke disability status scale

\begin{tabular}{|c|c|c|c|c|c|c|}
\hline & \multicolumn{3}{|c|}{$\begin{array}{l}\text { Oxygen group }(n=60) \\
\text { Number of patients }\end{array}$} & \multicolumn{3}{|c|}{$\begin{array}{l}\text { Placebo group }\left(n=57 / 56^{*}\right) \\
\text { Number of patients }\end{array}$} \\
\hline & Improved & Deteriorated & Unchanged & Improved & Deteriorated & Unchanged \\
\hline $\begin{array}{l}\text { Pre-study to post-study } \\
\text { Pre-study to six months } \\
\text { Pre-study to one year }\end{array}$ & $\begin{array}{l}0 \\
1 \\
1\end{array}$ & $\begin{array}{r}1 \\
9 \\
16\end{array}$ & $\begin{array}{l}59 \\
50 \\
43\end{array}$ & $\begin{array}{l}0 \\
0 \\
0\end{array}$ & $\begin{array}{r}1 \\
9 \\
15\end{array}$ & $\begin{array}{l}56 \\
47 \\
41\end{array}$ \\
\hline
\end{tabular}

${ }^{*} n=57$ at pre-study and post-study, $n=56$ at six months and one year, in tables 1-4.

Table 2 Improvement in Kurtzke functional systems scale

\begin{tabular}{|c|c|c|c|c|}
\hline & \multicolumn{2}{|c|}{$\begin{array}{l}\text { Oxygen group }(n=60) \\
\text { Number of patients }\end{array}$} & \multicolumn{2}{|c|}{$\begin{array}{l}\text { Placebo group }\left(n=57 / 56^{*}\right) \\
\text { Number of patients }\end{array}$} \\
\hline & $\begin{array}{l}\text { Improved at } \\
6 \text { months }\end{array}$ & $\begin{array}{l}\text { Improved at } \\
\text { I year }\end{array}$ & $\begin{array}{l}\text { Improved at } \\
6 \text { months }\end{array}$ & $\begin{array}{l}\text { Improved at } \\
1 \text { year }\end{array}$ \\
\hline \multicolumn{5}{|l|}{ Objective items: } \\
\hline Pyramidal function & 1 & 0 & 0 & 0 \\
\hline Cerebellar function & 0 & 1 & 1 & 2 \\
\hline Brainstem function & 1 & 3 & 1 & 1 \\
\hline Sensory function & 2 & 2 & 0 & 0 \\
\hline Visual function & 2 & 1 & 0 & 0 \\
\hline Mental function & 0 & 0 & 0 & 0 \\
\hline \multicolumn{5}{|l|}{ Subjective item: } \\
\hline Bowel/bladder function & $13+$ & 10 & $3+$ & 4 \\
\hline
\end{tabular}

$\dagger=$ significant difference $(p<0.05$, chi-square test $)$. 
Table 3 Deterioration in Kurtzke functional systems scale

\begin{tabular}{|c|c|c|c|c|}
\hline & \multicolumn{2}{|c|}{$\begin{array}{l}\text { Oxygen group }(n=60) \\
\text { Number of patients deteriorated at }\end{array}$} & \multicolumn{2}{|c|}{$\begin{array}{l}\text { Placebo group }\left(n=57 / 56^{*}\right) \\
\text { Number of patients deteriorated at }\end{array}$} \\
\hline & 6 months & 1 year & 6 months & 1 year \\
\hline \multicolumn{5}{|l|}{ Objective items: } \\
\hline Pyramidal function & 4 & 14 & 5 & 15 \\
\hline Cerebellar function & 5 & $5 \dagger$ & 5 & $15 t$ \\
\hline Brainstem function & 3 & 5 & 3 & 6 \\
\hline Sensory function & 1 & 1 & 5 & 7 \\
\hline Visual function & 2 & 2 & 0 & 1 \\
\hline Mental function & 1 & 1 & 0 & 1 \\
\hline \multirow{2}{*}{$\begin{array}{l}\text { Subjective item: } \\
\text { Bowel/bladder function }\end{array}$} & & & & \\
\hline & 4 & 10 & 8 & 9 \\
\hline
\end{tabular}

$\dagger=$ significant difference $(\mathrm{p}<0.05$, chi-square test $)$.

Table 4 Relapse history

\begin{tabular}{lll}
\hline & \multicolumn{2}{l}{ Total number of relapses in } \\
\cline { 2 - 3 } & $\begin{array}{l}\text { Oxygen group } \\
(n=60)\end{array}$ & $\begin{array}{l}\text { Placebo group } \\
\left(n=57 / 56^{*}\right)\end{array}$ \\
\hline In year pre-study & 17 & 21 \\
In year post-study & 18 & 17 \\
\hline
\end{tabular}

No significant differences.

benefit from the therapy. ${ }^{1}$ The median time that this improvement had lasted was 7 weeks in the oxygen group and 6 weeks in the control patients.

\section{Evoked potential studies}

A total of 29 patients in the oxygen group and 28 in the placebo group had visual and cervical/cortical somatosensory evoked potentials performed before and after treatment. Twenty seven oxygen patients and 25 controls had the studies repeated at 6 months.

Non-parametric statistical analysis was performed both within-group (Wilcoxon matched-pairs signedrank test) and between-group (Mann Whitney $U$ test). Analysis was made on the pre-study to poststudy data and the pre-study to 6 month data.

No significant differences were found either within or between treatment groups in any parameter (latency and amplitude of the major wave form components) of the cervical or cortical somatosensory evoked potentials. No significant differences were found either within or between treatment groups in the P100 or N2-N1 latency of the visual evoked potential.

The amplitude of the visual evoked potential showed a highly significant reduction in the oxygen group from the pre-study to the post-study recording. This change was found in both right and left eyes and was not found in the placebo group $(p=0.003$ left eyes, $p=0.006$ right eyes, Wilcoxon matched-pairs signed-rank test). The amplitude reduction was no longer significant at 6 months. There was no significant correlation between the amplitude change and the patient's age, disease duration or initial Kurtzke DS score, (Spearmans non-parametric rank correlation coefficients). There was no significant reduction in patients with chronic static disease. There was a highly significant reduction in patients with chronic progressive multiple sclerosis, ( $p=0.002$ left eyes, $p=0.004$ right eyes, Wilcoxon matched-pairs signed-rank test).

\section{Urodynamic assessment}

Twenty patients in both groups completed pre-study and post-study assessments and 18 oxygen patients and 15 control patients completed an additional assessment at 6 months.

The results of the detailed urinary history failed to reveal any significant improvement in any individual symptom between the treatment groups, either poststudy or at 6 months. There was a greater trend for urgency and urge incontinence to improve in the oxygen group but the group differences failed to reach statistical significance. However, the total number of patients that reported improvement in at least one symptom was significantly greater in the oxygen group than in the placebo group both post-study and at 6 months, $(9 \mathrm{v} .2$ post-study, $p<0.05$ and $8 \mathrm{v} .1$ at 6 months, $p<0.05$ ).

A number of urodynamic parameters were compared between the groups; bladder compliance, volume to first uninhibited contraction, maximum pressure of uninhibited contraction, maximum pressure of void, volume to first desire to void, maximum bladder capacity, void flow rate and presence/absence of uninhibited contractions. None of these parameters showed any significant improvement between the groups, either post-study or at 6 months. Maximum bladder capacity and void flow rate showed a significant decrease in the oxygen group pre-study to post-study, $(p=0.003$ for bladder capacity and $p=0.004$ for void flow rate, Wilcoxon matched-pairs signed-rank test). 


\section{Psychometric tests}

All 50 selected patients from both groups completed the test battery pre- and post-trial. There were highly significant improvements in both groups between the pre-study and post-study trials of all tests except the trail making test. There were no significant betweengroup differences indicating that hyperbaric oxygen had no effect on higher mental function as tested by our battery. The improvements may reflect either a placebo and/or a practice effect.

\section{Lymphocyte sub-populations}

All selected patients in both groups had measurements of OKT3, OKT4 and OKT8 made pre-study, Day 8, Day 18 and at 3 months.

The oxygen group showed no significant changes in OKT3, OKT4 or OKT8 counts during the duration of the study. The placebo group showed a significant fall in OKT8 levels during the treatment period ( $p=0.048$, Wilcoxon matched-pairs signed-rank test, at Day 18) but the level had returned to pre-study values at the 3 month assessment.

\section{Discussion}

Two double-blind controlled studies have reported long term results of the use of hyperbaric oxygen in chronic multiple sclerosis. Fischer et al $^{13}$ found deterioration in two patients $(12 \%)$ of the oxygen group compared with 11 control patients $(55 \%)$ at one year. However, the deterioration rate in the placebo group in this study is much higher than is usually seen in studies of the natural history of the disease. These results were not supported by a study by Neiman et $a l^{4}$ which found no significant difference in disease progression at 6 months in a small study involving 19 patients. In an addendum to a recent publication Wiles et l $^{8}$ state that there was no significant difference in major or subjective outcomes between the treatment groups at 6 months in their study which involved 84 patients. The present study confirms that hyperbaric oxygen has had no major effect on the rate of disease progression and has had no effect on relapse rate. The only significant finding was of less cerebellar deterioration in the oxygen group as measured by the Kurtzke functional systems scale at 1 year. The Kurtzke scale is not a particularly accurate measure of cerebellar disability and the result of the more detailed objective testing in the study of Wiles et $a l^{8}$ is awaited with interest. It must also be remembered that when multiple comparisons are made chance findings can occur that are not necessarily of biological significance or useful for the individual patient. However, if this finding can be confirmed then it may be of benefit for patients as there is no consistently successful treatment for cerebellar dysfunction.
The short term subjective benefit in bowel/bladder function in the oxygen group on the Kurtzke scale ${ }^{1}$ was sustained at 6 months. A more detailed and accurate urinary history taken in a proportion of patients failed to confirm improvement in any individual symptom although more oxygen patients reported improvement in at least one symptom compared to the placebo patients, both post-study and at 6 months. Conversely, there were no improvements in objective urodynamic assessments. Two parameters (bladder capacity and void flow rate) showed a significant deterioration post-study in the oxygen group.

The psychometric battery failed to show any oxygen related improvements and the study of lymphocyte sub-populations also failed to show any oxygen related effects. The fall in OKT8 levels in the placebo group is of doubtful significance to the present study.

The lack of improvement in evoked potentials is compatible with the recent study by Neiman et al. ${ }^{4}$ It is in contrast to the single case report of improvement in a visual evoked potential during hyperbaric oxygen treatment by Hammond and Ibarra. ${ }^{14}$ The significant reduction in amplitude of the visual evoked potential after oxygen treatment is of interest. The most likely anatomical site for an amplitude reduction without latency change and without changes in the somatosensory responses is the retina. Hyperbaric oxygen is known to cause retinal damage, probably as a result of retinal vasoconstriction and consequent ischaemia and/or direct oxygen toxicity. ${ }^{15-17}$ This effect usually occurs at higher oxygen pressures for longer periods than employed in this study ${ }^{16}$ but Nichols et al ${ }^{17}$ felt that previous retrobulbar neuritis increased the vulnerability of the retina to oxygen toxicity. In the present study patients with chronic progressive disease were particularly prone to amplitude change which may indicate that on-going disease activity predisposes to oxygen damage. This effect was reversible after 20 sessions but the finding may be of relevance to patients exposed to multiple follow-up sessions of hyperbaric oxygen.

In summary, we have found subjective improvement in urological symptoms which was sustained for 6 months. This has not been supported by objective urodynamic studies and indeed some urological parameters showed a deterioration after oxygen. The only longer term benefit may be slowing of cerebellar deterioration, which will need confirmation from other studies. The possibility of mild benefit for a few patients must be balanced against the problems involved with this treatment. There are many practical difficulties in treating large numbers of patients in a compression chamber. There is a high incidence of minor side effects and a risk, albeit small, of major problems associated with oxygen toxicity. The ther- 
apy is time consuming and tiring for the patients. Overall we feel it is unlikely that hyperbaric oxygen will play any practical role in the management of a patient with chronic multiple sclerosis.

We thank the following for help and advice: Dr Ian Schofield for the evoked potential tests; Mr Peter Ramsden and Ms Ann Gallagher for the urodynamic assessments; Mr John Welch for the psychometric battery; Dr Graham Bird and his staff for measurements of the lymphocyte subsets and Mrs Sally Reece for typing the manuscript.

\section{References}

1 Barnes MP, Bates D, Cartlidge NEF, et al. Hyperbaric oxygen and multiple sclerosis: short term results of placebo-controlled, double-blind trial. Lancet 1985;i: 297-300.

2 Kurtzke JF. Further notes on disability evaluation in multiple sclerosis with scale modifications. Neurology 1965;15:654-61.

3 Wood J, Stell R, Unsworth I, Lance JW, Skuse N. A double-blind trial of hyperbaric oxygen in the treatment of multiple sclerosis. Med J Aust 1985;143: 238-41.

4 Neiman J, Nilsson BY, Barr PO, Perrins DJD. Hyperbaric oxygen in chronic progressive multiple sclerosis: visual evoked potentials and clinical effects. $J$ Neurol Neurosurg Psychiatry 1985;48:497-500.

5 Massey EW, Shelton DL, Pact V, et al. Hyperbaric oxygen in multiple sclerosis: double-blind crossover study in 18 patients. Neurology 1985;35,suppl 1:104.

6 Murthy KN, Maurice PB, Wilmeth JB. Double-blind randomised study of hyperbaric oxygen versus placebo in multiple sclerosis. Neurology 1985;35,suppl 1:104.

7 Slater GE, Anderson DA, Sherman R, Ettinger MG, Haglin J, Hitchcock C. Hyperbaric oxygen and multiple sclerosis: a double-blind controlled study. Neurology 1985;35,suppl 1:315.

8 Wiles CM, Clarke CRA, Irwin HP, Edgar EF, Swan AV. Hyperbaric oxygen in multiple sclerosis: a doubleblind trial. Br Med J 1986;292:367-71.

9 Reitan AM. Validity of the trail making test as an indicator of organic brain damage. Percept Mot Skills 1958;8:271-6.

10 Rey A. L'examen Clinique en Psychologie. Paris: Presses Universitaire de France, 1964.

11 Benton AL. The measurement of aphasic disorders. In: Ceceres Velasquez, ed. Aspectos patologicas de langage. Lima, Centro Neuropsicologico, 1973.

12 Beatty PA, Gange JJ. Neuropsychological aspects of multiple sclerosis. J Nerv Ment Dis 1977;164:42-50.

13 Fischer BH, Marks M, Reich T. Hyperbaric oxygen treatment of multiple sclerosis. A randomised, placebo-controlled, double-blind study. $N$ Engl J Med 1983;308:181-6.

14 Hammond EJ, Ibarra EL. Evoked potentials after hyperbaric oxygen treatment of multiple sclerosis. $N$ Engl J Med 1983;309:241-2.

15 Saltzman HA, Hart L, Sicker HO, Duffy EJ. Retinal vascular response to hyperbaric oxygenation. JAMA 1965;191:114-6.

16 Behnke AR, Forbes HS, Motley EP. Circulatory and visual effects of oxygen at 3 atmospheres pressure. $\mathrm{Am}$ $J$ Physiol 1936;114:436-42.

17 Nichols CW, Lambertsen CJ, Clark JM. Transient unilateral loss of vision associated with oxygen at high pressure. Arch Ophthalmol 1969;81:548-52. 